\title{
From adrenarche to aging of adrenal zona reticularis: precocious female adrenopause onset
}

\author{
Emanuelle Nunes-Souza ${ }^{1,2,3}$, Mônica Evelise Silveira ${ }^{4}$, Monalisa Castilho Mendes ${ }^{1,2,3}$, Seigo Nagashima ${ }^{5,6}$, \\ Caroline Busatta Vaz de Paula ${ }^{5,6}$, Guilherme Vieira Cavalcante da Silva ${ }^{5,6}$, Giovanna Silva Barbosa ${ }^{5,6}$, \\ Julia Belgrowicz Martins ${ }^{1,2}$, Lúcia de Noronha ${ }^{5,6}$, Luana Lenzi ${ }^{7}$, José Renato Sales Barbosa ${ }^{1,3}$, \\ Rayssa Danilow Fachin Donin ${ }^{3}$, Juliana Ferreira de Moura ${ }^{8}$, Gislaine Custódio ${ }^{2,4}$, Cleber Machado-Souza ${ }^{1,2,3}$, \\ Enzo Lalli9 and Bonald Cavalcante de Figueiredo ${ }^{1,2,3,10}$

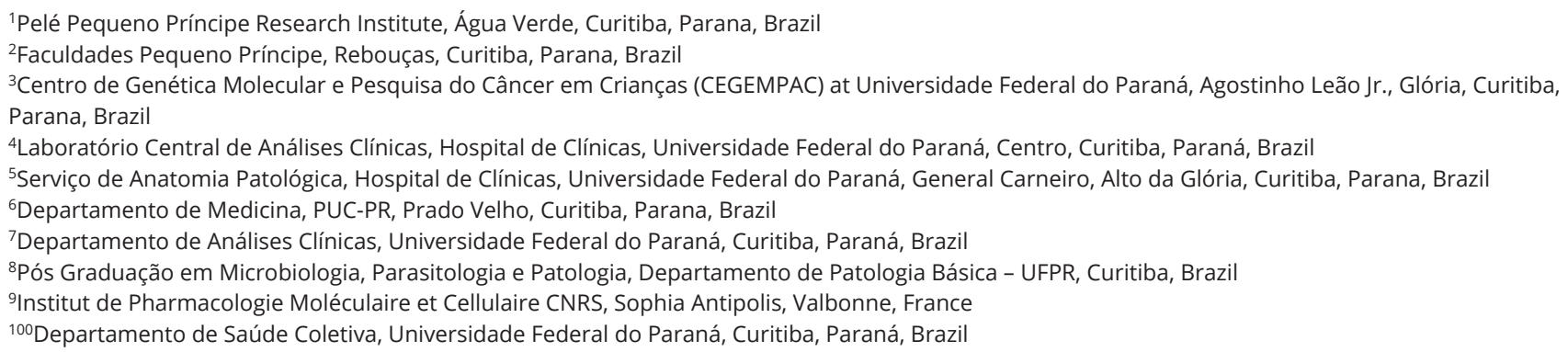

Correspondence should be addressed to B C de Figueiredo: bonaldf@yahoo.com.br

\begin{abstract}
Objective: Adaptive changes in DHEA and sulfated-DHEA (DHEAS) production from adrenal zona reticularis (ZR) have been observed in normal and pathological conditions. Here we used three different cohorts to assess timing differences in DHEAS blood level changes and characterize the relationship between early blood DHEAS reduction and cell number changes in women ZR.

Materials and methods: DHEAS plasma samples $(n=463)$ were analyzed in 166 healthy prepubertal girls before pubarche ( $<9$ years) and 324 serum samples from 268 adult females (31.9-83.8 years) without conditions affecting steroidogenesis. Guided by DHEAS blood levels reduction rate, we selected the age range for ZR cell counting using DHEA/ DHEAS and phosphatase and tensin homolog (PTEN), tumor suppressor and cell stress marker, immunostaining, and hematoxylin stained nuclei of 14 post-mortem adrenal glands.

Results: We confirmed that overweight girls exhibited higher and earlier DHEAS levels and no difference was found compared with the average European and South American girls with a similar body mass index (BMI). Adrenopause onset threshold (AOT) defined as DHEAS blood levels $<2040 \mathrm{nmol} / \mathrm{L}$ was identified in $>35 \%$ of the females $>40$ years old and associated with significantly reduced ZR cell number (based on PTEN and hematoxylin signals). ZR cell loss may in part account for lower DHEA/DHEAS expression, but most cells remain alive with lower DHEA/DHEAS biosynthesis.

Conclusion: The timely relation between significant reduction of blood DHEAS levels and decreased ZR cell number at the beginning of the 40 s suggests that adrenopause is an additional burden for a significant number of middle-aged women, and may become an emergent problem associated with further sex steroids reduction during the menopausal transition.
\end{abstract}

\section{Key Words}

- dehydroepiandrosterone

- DHEAS

- sulfateddehydroepiandrosterone

- DHEA-S

- adrenarche

- adrenopause

- phosphatase and tensin homolog

- PTEN

- female 


\section{Introduction}

Our current understanding of the three functionally and morphologically distinct adrenocortical layers, and especially the development and maturation of the human androgenic layer comprising the fetal zone during fetal life and the zona reticularis (ZR) after puberty, has been enriched by the contributions from numerous researchers through landmark studies $(1,2,3)$. Many transcription factors, growth factors, and hormones have been implicated in adrenocortical cell development and the control of steroidogenic function $(4,5)$. Specifically, a major role has been described for the integrated network of transcription factors that regulate adrenal zonation and steroidogenesis, including Wilms' tumor-1, Steroidogenic Factor-1, Dosage-sensitive sex reversal, adrenal hypoplasia congenita, X-linked-1 (DAX1), PBX1, and CITED2 (3).

Cholesterol, derived from low-density lipoprotein or de novo adrenal synthesis, constitutes the primary source for production of two major steroid products in the fetal zone, namely DHEA and DHEA sulfate (DHEAS), which serve as estrogen precursors essential for the maintenance of pregnancy $(5,6)$. Onset of zonal differential steroidogenic activity and strong remodeling of the adrenal gland occur after birth, leading to programmed cell death of the fetal zone as reflected by a rapid decrease in DHEA and DHEAS blood levels during the first three postnatal months (6). Over the following five years, corresponding to the pre-adrenarche phase, the zona glomerulosa and zona fasciculata become well differentiated, whereas cells of the islands of zona reticularis remain quiescent with very low production of DHEA and DHEAS $(4,6)$. We focused on blood DHEAS levels because it is the most abundant adrenocortical steroid in blood, measurement is widely available and is more frequently reported than DHEA.

Adrenarche constitutes a period of adaptive response to stress from prepuberty to early puberty, associated with maturation of the hypothalamic-pituitary-adrenal axis leading to secondary sexual signs $(2,4,7)$. Accelerated weight gain in infancy has been associated with premature adrenarche, which is also associated with a greater risk of developing metabolic syndrome later in life $(8,9,10)$.

Most boys and girls from Leipzig, Germany, at 7 and 8 years of age presented with similar DHEAS levels $(<2980 \mathrm{nmol} / \mathrm{L})$ (12). In a study on children with normal BMIs in Kiel, Germany, many individuals aged 6-8 years presented with DHEAS levels $<1360 \mathrm{nmol} / \mathrm{L}$ for girls. Girls with normal BMI from Lyon, France presented with DHEAS levels $<1630 \mathrm{nmol} / \mathrm{L}$ at 7 years of age (12). Normal children from Argentina (predominantly of Italian descent) presented with levels $<810 \mathrm{nmol} / \mathrm{L}$ prior to 8 years of age (13) whereas those from Siena (Italy) at the same ages exhibited approximately $540 \mathrm{nmol} / \mathrm{L}$ DHEAS (14).

Although changes regulating steroid biosynthesis from early infancy to late puberty still represent an intriguing mystery, modern endocrine physiology has not yet characterized the mechanism underlying adrenopause. Three important conclusions can be drawn regarding blood DHEAS levels from the Leipzig study (15): (1) a more significant decrease in DHEAS occurs after the age of 30 years; (2) DHEAS levels are significantly higher in males, and the women over 40 years old presented DHEAS levels $>2990 \mathrm{nmol} / \mathrm{L}$; and (3) most individuals, especially men, retained levels above $2071 \mathrm{nmol} / \mathrm{L}$ until their seventh decade. In comparison, a study with patients from a dermatologic clinic in New York reported higher DHEAS levels for men and women over 40 years old (16), that is, above $3090 \mathrm{nmol} / \mathrm{L}$ in women. Moreover, significant DHEAS differences were found among 2886 women aged 42-52 years from different ethnic groups living in various regions of the United States (Boston, Chicago, Detroit area; Los Angeles; Newark; Pittsburgh; and Oakland). Notably, African American and Hispanic individuals exhibited the lowest levels, $<2440$ and $<2990$ nmol/L, respectively (16). DHEAS level differences were also reported within the same ethnic group in Peru, where women living at high altitude presented lower levels than those living at sea level (17).

Brazilians are an extremely heterogenous population with genetic admixture between Amerindians, Europeans and Africans (18). The Paraná state is one of the three southernmost states, with a predominant European ancestry.

Considering blood DHEAS levels $<2040 \mathrm{nmol} / \mathrm{L}$ as the adrenopause onset threshold (AOT), we investigated at which ages when at least $>35 \%$ of the females present AOT, possible ZR cell number changes, and whether early adrenarche timing is different in Brazilian compared to European girls. AOT was selected based on similar levels found in the beginning of adrenarche ( $<9$ years), and because it was associated with significant further reduction in the following years, which was demonstrated using the minimum, first quartile, median, third quartile, and maximum values. https://ec.bioscientifica.com https://doi.org/10.1530/EC-20-0416 (c) 2020 The authors Published by Bioscientifica Ltd
This work is licensed under a Creative Commons Attribution-NonCommercial-NoDerivatives 4.0 Internationab dicense.ifica.com at 04/26/2023 11:33:09AM 


\section{Methods}

\section{Subjects selected for morning blood DHEAS determination}

\section{Girls}

DHEAS and BMI were evaluated in healthy girls between 3 and 8 years of age $(\mathrm{N}=166)$. Morning blood samples were drawn as part of a longitudinal observational study of baseline DHEAS data from children enrolled in the Surveillance Cohort Study for Cancer Risk (SCSCR) (Clinal trials: Brazilian registry (Rebec) U1111-1196-4533) following parental or guardian consent (19). Girls were eligible for the SCSCR study if they met the following criteria: tested positive for a low penetrance germline TP53 p.R337H variant, underwent periodical medical, DHEAS, and imaging exams. SCSCR was approved by the Ethics Committee of Hospital de Clínicas at Federal University (2005), Pequeno Príncipe Hospital (2005 and 2009), and the Federal Ethics Committee (CONEP) in Brasilia (2005, 2009), under codes CAA 0023.0.208.000-05 from 2005, and CAAE 0612.0.015.000-08, from 2009).

All girls were examined at different ages, resulting in 463 morning plasma samples (07:00-08:30) at mean intervals ranging from 4 to 6 months. Samples from overweight $(n=146)$, underweight $(n=14)$, and normal weight $(n=303)$ girls were included. Exclusion criteria were as follows: girls small for gestational age (birth weight $<2.5 \mathrm{~kg}$ ), born prematurely, diagnosed with any type of cancer, congenital adrenocortical disease, or any syndrome, pubertal onset in girls prior to 8 years, and blood samples collected outside of the morning testing time. BMI-for-age was calculated as indicated by the CDC calculator for children (20). Normal, under-, and overweight reference BMI were defined based on WHO reference data (21).

\section{Adult females}

Fasting blood DHEAS samples $(n=324)$ from 268 adult females aged 31.9-83.8 years were determined by the Central Laboratory (Unidade de Apoio Diagnóstico) of Hospital de Clínicas of Federal University of Paraná outpatient clinic. Use of these data was approved by the Hospital de Clínicas Ethics Committee (CAAE 53403416.4.0000.0096 in 2016). Data from patients presenting with adrenal pathology, any cancer, endocrine, autoimmune or metabolic syndrome, infection, terminal disease, treatment with steroids or inhibitors of steroid biosynthesis were excluded.

\section{Measurement of DHEAS}

As standard procedure, only morning fasting blood samples from girls and adult females were used and assessed using a chemiluminescent microparticle immunoassay (Architect Abbott), which has a wide range of detection (80-40,710 nmol/L).

\section{Adrenal glands from autopsies}

Use of adrenal glands embedded in paraffin from the Department of Pathology repository (autopsies performed from 2000 to 2012) at Hospital de Clínicas of Federal University of Paraná was approved by the Health Sciences Sector Ethics Committee (CAAE78692617.4.0000.0102). The histological profile of the adrenal cortex was evaluated by immunohistochemistry. The glands $(n=14)$ were selected from 14 post-mortem females, comparing the 16-20 year-group with the ages with early decrease of blood DHEAS, excluding all cases with infectious disease, adrenal pathology, any type of cancer, endocrine, autoimmune or advanced terminal disease, or use of steroids.

\section{Immunohistochemistry for DHEA/DHEAS and PTEN}

Adrenal glands from deceased patients unrelated to adrenal diseases were evaluated by immunohistochemical analysis following staining for DHEA/DHEAS and phosphatase and tensin homolog (PTEN) protein expression in the ZR. PTEN protein immunostaining was used as a control for cellular preservation and as a biomarker that becomes overexpressed in response to stressful oxidative conditions before death $(22,23)$. Cell counting and preservation of cellular structure were estimated using sections stained with hematoxylin (Newprov, Pinhais, Brazil).

Despite the limitation of our immunohistochemical data associated with the use of post-mortem glands and small number of adrenals, all samples were obtained under the same conditions (time frame to perform autopsy after death, tissue fixation and paraffin-embedded preparation) and were used within the same time frame to perform tissue fixation and microscopy analyses.

Full immunostaining protocol was performed as described, with minor modifications (24, 25). Briefly, adrenal gland tissue sections ( $4 \mu \mathrm{m}$ thick) were mounted on positively loaded glass slides and stained using the immunoperoxidase technique. The primary antibodies, anti-recombinant DHEA 3F5 (4) (pH 6.0, undiluted) and

This work is licensed under a Creative Commons Attribution-NonCommercial-NoDerivatives 4.0 Internationab License.ifica.com at 04/26/2023 11:33:09AM 
mouse monoclonal anti-PTEN 28H6 (Vision BioSystems Novocastra $\left.{ }^{\circledR}\right)(\mathrm{pH}$ 6.0, 1:100 dilution), were incubated overnight at $4^{\circ} \mathrm{C}$. After washing, the tissue sections were incubated with the secondary polymer (Reveal Polyvalent HRP-DAB Detection System, Spring Bioscience, Pleasanton, CA, USA) for $25 \mathrm{~min}$ at $21-23^{\circ} \mathrm{C}$. Sections were developed using complex 2,3,-diaminobenzidine (Reveal Polyvalent HRP-DAB Detection System, Spring Bioscience) + DAB chromogen concentrate (Reveal Polyvalent HRP-DAB Detection System) for $3 \mathrm{~min}$, followed by counterstaining with Harris hematoxylin (Newprov, Pinhais, Brazil).

The immunoreactive DHEA/DHEAS cells were evaluated using the Axio Scan.Z1 slide scanner (Zeiss ${ }^{\circledR}$, Jena, Germany), at a $40 \times$ magnification. Ten photos were taken from each adrenocortical layer. A standard image of each layer containing appropriate levels of each set of immunohistochemical signals was chosen for use as a 'mask', determined by the Image Pro Plus ${ }^{\circledR} 4.5$ morphometric analysis program (Media Cybernetics ${ }^{\circledR}$, Rockville, MD, USA). Tissue expression for each biomarker was obtained by quantitative analysis (morphometry). Immunopositive areas of each photomicrograph, in square micrometers, were transformed into a percent by high power field value (HPF). We also counted hematoxylin and immune-positive cells (DHEA/DHEAS and PTEN) per HPF, selecting cells with at least the lowest detectable color above the background. This HPF percentage analysis (obtained at $\sim 400 \times$ ) was determined by using Zen 3.0 blue edition ZEN Lite software for Windows (ZEISS ${ }^{\circledR}$ ). Changes in ZR cell number were assessed using two approaches: (1) counting hematoxylin-stained cells (negative for DHEA/ DHEAS or PTEN, (2) counting immunoreactive positive and negative cells for DHEA/DHEAS and for PTEN per $10 \times \mathrm{HPF}$.

\section{Statistical analysis for DHEAS levels}

The DHEAS data were transferred to an Excel 2007 spreadsheet (Microsoft Corporation) and analyzed using SPSS version 17.0 (IBM). Quantitative variables were evaluated in relation to the central tendency and dispersion measures. For qualitative data, the absolute and relative frequencies were obtained. Variables were tested for normality using the Komolgorov-Smirnov test. Comparisons between nonparametric variables were performed using the Mann-Whitney and KruskalWallis test. Blood DHEAS quantifications were evaluated graphically as their dispersion in relation to age. The dispersion of DHEAS levels was also assessed in relation to BMI and age, and compared by trendlines using quadratic fit. Multivariate analysis using linear regression investigated the decreased DHEAS in each age range. Mean and S.D. values for ZR cell number was evaluated using independent Student's $t$-test. A $P$ value $<0.05$ was considered statistically significant.

\section{Results}

\section{DHEAS in girls according to BMI}

Blood samples (1-3) were collected from the same girls (at different ages) from one month to 8 years. Only fasting morning plasma DHEAS levels were used in this study (Fig. 1). DHEAS mean values stratified according to three BMI categories (underweight, normal weight) presented higher mean values for overweight than normal or underweight girls $(P<0.01)$, as shown in Table 1.

\section{Serum DHEAS in adult females}

Cautious selection of samples was necessary to exclude endocrine pathologies, or patients using any steroid or medications that affect DHEA and DHEAS synthesis in any of the three cohorts. The age of women $(n=268)$ ranged from 31.9 to 83.8 years. It was observed significant

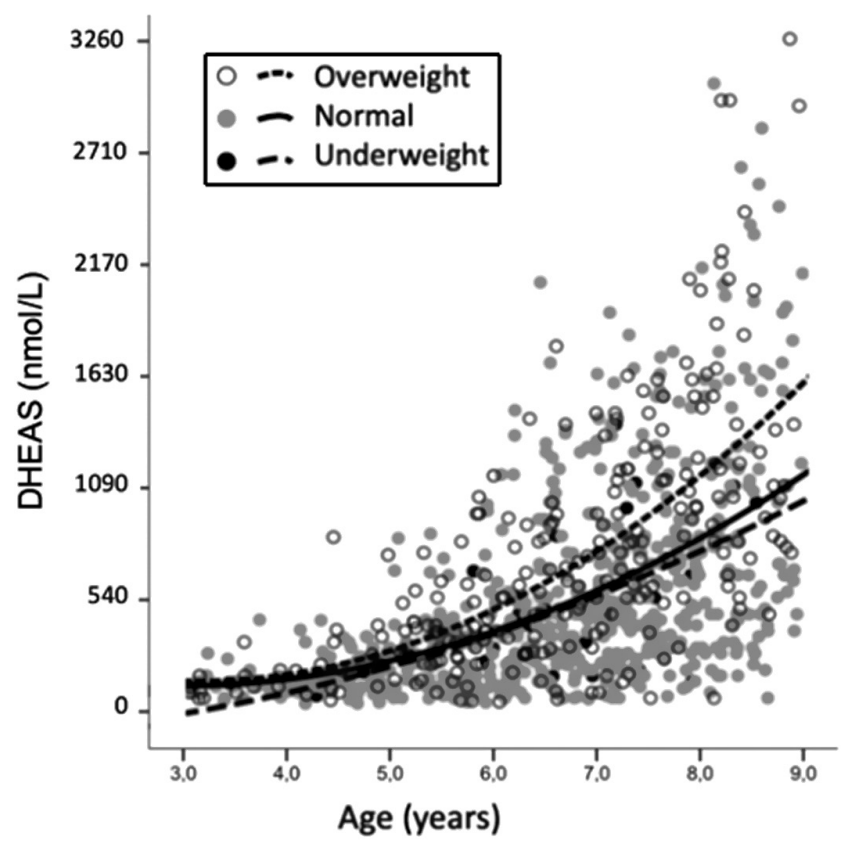

Figure 1

Scatter plot of DHEAS values. DHEAS levels are shown in 166 girls from 3 up to 8 years of age (463 samples in total). Groups (underweight, normal and overweight) were compared by trendlines using quadratic fit.

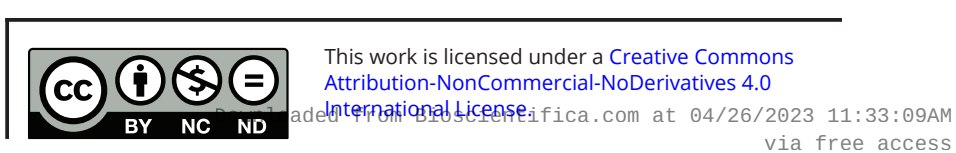


Table 1 DHEAS mean values stratified by BMI values in girls.

\begin{tabular}{|c|c|c|c|}
\hline \multirow[b]{2}{*}{ BMI Status } & \multicolumn{2}{|c|}{ DHEAS $\left(\mathrm{nmol} / \mathrm{L}^{\mathrm{a}}\right)$} & \multirow[b]{2}{*}{ P value ${ }^{b}$} \\
\hline & Mean & SD & \\
\hline Underweight & 490 & 360 & \\
\hline Normal & 530 & 510 & \\
\hline Overweight & 700 & 590 & $<0.01$ \\
\hline
\end{tabular}

aTo convert from SI to conventional units, divide by the factor 2.714

${ }^{\mathrm{b} K r u s k a l-W a l l i s ~ t e s t, ~ a g a i n s t ~ t h e ~ n o r m a l ~ w e i g h t . ~}$

decrease in DHEAS in the age group of $41-45$ year, when $>35 \%$ of all women older than 40 years presented blood DHEAS $<2040 \mathrm{nmol} / \mathrm{L}$. This was defined as the AOT which further continues decreasing in older ages and below the threshold (Fig. 2 and Table 2).

\section{DHEA/DHEAS immunostaining and cell counts in post-mortem adrenal cortex}

The primary anti-DHEA antibody recognizes DHEA and DHEAS (24), hereby described as DHEA/DHEAS immunepositive cells, which were evaluated in the adrenal cortex of 14 post-mortem adrenal glands from individuals between the ages of $16-20(n=8)$ and $41-43$ years $(n=6)$. Photomicrographs of the adrenal cortex are shown in Fig. 3. DHEA/DHEAS tissue expression in the ZR was measured by the size of the positive area in square micrometers $\left(\mu \mathrm{m}^{2}\right)$. The mean immunostaining expression level in the ZR was higher than in zona fasciculata or zona glomerulosa in all glands (data not shown). DHEA/DHEAS expression decreased in ZR of older women (43 years) compared to younger ages. However, due to the reduced number of adrenal glands in each age group, and the variations in the expression data, the difference was not significant $(P=0.07)$.

From the same group of adrenals $(n=14)$, tissue sections were also incubated with anti-PTEN for ages from 19 to 43 years. Probably given the nature of the conditions characterized by a high likelihood of oxidative stress prior to and following death, most adrenocortical cells exhibited PTEN immunoreactive cells (Fig. 3).

Table 3 presents data for cell counting performed in the ZR including negative- and positive-immunostained cells for DHEA/DHEAS or PTEN in 14 adrenals (7 in the 16-20 years-old group and 7 in the 40-43year-old group). Negative cells were also counted according to the hematoxylin staining signal. Using this approach, a significant mean cell number reduction was observed only in the older age group (total cell number counting considering PTEN and hematoxylin signals). Considering only the PTEN-positive cell counting was not different $(P<0.8)$.
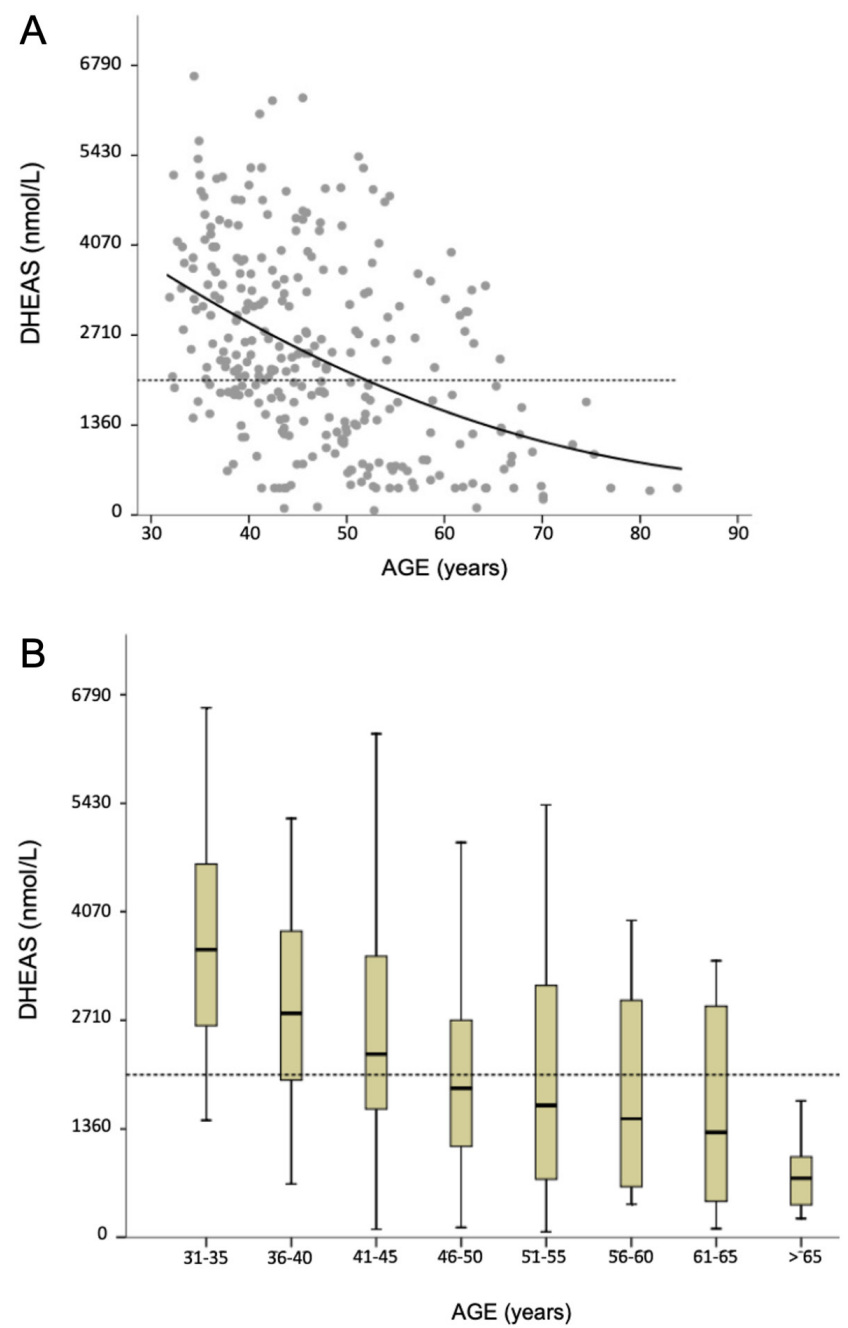

Figure 2

(A) Scatter plot of serum DHEAS values in adult women. Groups were compared by trendlines using quadratic fit. The horizontal dashed line was placed on level $2040 \mathrm{nmol} / \mathrm{L}$. (B) Box plot associating DHEAS levels and age in women and summarizing the minimum, first quartile, median, third quartile, and maximum values.

Given to the low number of adrenal glands, and the low DHEA/DHEAS signal, the mean cell number difference between both age groups was not significant considering only DHEA/DHEAS-positive cells $(P<0.19)$ or the total (DHEA/DHEAS + negative cells detected with hematoxylin) $(P<0.22)$.

\section{Discussion}

This study evaluated the increase in DHEAS until 8 years of age in girls, excluding all girls with pubarche, thelarche, or any sign of activated puberty. At the beginning of 
Table 2 Serum DHEAS reduction rate and percentage of adult females presenting with serum DHEAS $<2040 \mathrm{nmol} / \mathrm{L}$.

\begin{tabular}{|c|c|c|c|c|}
\hline & & & & Females, $\boldsymbol{n}^{\mathrm{a}}(\%)$ \\
\hline Age range (years) & Beta $(95 \% \mathrm{Cl})$ & S.E. & P value & DHEAS $<2040 \mathrm{nmol} / \mathrm{L}$ \\
\hline Age 31-35 & $11.914(8.540 ;-4.896)$ & 8.540 & 0.164 & $28(10.7)$ \\
\hline Age $36-40$ & $-26.838(11.073 ;-48.635)$ & 11.073 & 0.016 & $69(25.8)$ \\
\hline Age 41-45 & $-38.752(10.920 ;-60.247)$ & 10.920 & $<0.0001$ & $94(35.3)$ \\
\hline Age 46-50 & $-55.901(11.757 ;-79.043)$ & 11.757 & $<0.0001$ & $152(56.8)$ \\
\hline Age 51-55 & $-58.336(12.112 ;-82.178)$ & 12.112 & $<0.0001$ & $162(60.5)$ \\
\hline Age 56-60 & $-69.109(15.241 ;-99.109)$ & 15.241 & $<0.0001$ & $167(62.5)$ \\
\hline
\end{tabular}

A negative beta indicates a decline of DHEAS with increasing age.

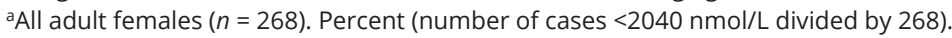

adrenarche children present signs of adult-type body odor, oily skin and hair, and pubic hair growth (19). Differences in timing of Tanner stages were not investigated in the present study. Adrenarche and pubarche constitute a causally related sequence (26). In our cohort, DHEAS levels began to increase more rapidly from 410 to $680 \mathrm{nmol} / \mathrm{L}$ at approximately 6 years of age in children with normal BMI, whereas obese children exhibited significantly increased blood DHEAS. Despite the small difference in the rate of DHEAS increase in the first year (6-7 years of age), we found small differences in blood DHEAS levels in girls at 7-8 years compared to those published previously for other ethnic groups $(12,13,14,27)$. Overall, the observed DHEAS increases in girls were comparable to prior reports in terms of timing and age-matched levels. Given that adrenarche onset does not occur earlier in Southern Brazil, earlier adrenopause onset is conceived as an isolated population-specific physiological condition likely related to genetic and geographical selective factors.

The adopted strategy to select adrenal age was based upon two findings. The first was the highest detected decay in blood DHEAS levels per year identified at the beginning of the fifth decade with a significant percent of adults (>35\%) with levels <2040 nmol/L (Fig. 2 and Table 2). We demonstrated that these indices may be useful to classify adrenopause onset, which in Southern Brazil occurs earlier. However, the metabolic impact of adrenopause on the adrenal cortex and other organs in women, and mainly during menopausal transition requires systematic studies to define the clinical consequences. To the best of our knowledge, no study has been published in the same geographic region associating clinical data and blood DHEAS levels <2040 nmol/L, probably because sex steroids from ovaries are still abundant in pre-menopausal women. Benetti-Pinto et al. (27) have reported similar DHEAS levels data in São Paulo (next to Paraná state). These authors presented control mean blood DHEAS levels $( \pm$ SD) from healthy women at $35.5 \pm 5.5$ years (regularly menstruating women) and $55.1 \pm 3.9$ years (postmenopausal women) as $2909 \pm 1460$ and $1499 \pm 720$ $\mathrm{nmol} / \mathrm{L}$, respectively. This wide variation in DHEAS levels suggests that a significant percent of women present DHEAS levels $<2040 \mathrm{nmol} / \mathrm{L}$ in the 40s. These events together, adrenopause and menopause, may accelerate the aging process and cause skin and vaginal atrophy, bone and muscle loss.

The adrenal ZR is the main source of low potency androgens in females, and this loss may have
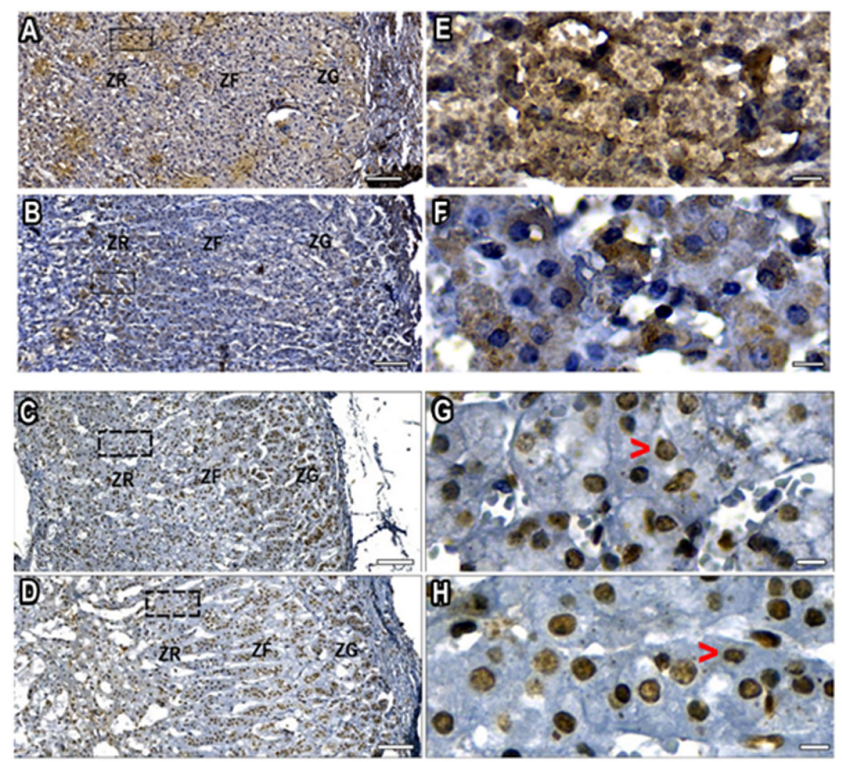

\section{Figure 3}

DHEA/DHEAS immunostaining-positive cells at age 16 years ( $A$ and $E$ ), and at the age with a significant reduction in DHEAS blood level, at 43 years (B and F). Scale bar $100 \mu \mathrm{m}$ (A and B) and $10 \mu \mathrm{m}$ (E and F). ZR, zona reticularis; $\mathrm{ZF}$, zona fasciculata; $\mathrm{ZG}$, zona glomerulosa. Nuclei are shown in blue (hematoxylin counterstained), DHEA/DHEAS are stained brown. PTEN immunostaining-positive nuclei (brown) at peak DHEAS blood level at 19 years ( $C$ and $G$ ), and at the age with the most intense DHEAS blood level reduction, at 43 years ( $D$ and $H$ ). Scale bar $100 \mu \mathrm{m}$ (C and $D)$ and 10 $\mu \mathrm{m}$ ( $\mathrm{G}$ and $\mathrm{H}$ ). The cytoplasmic PTEN signal was either not detectable in most cells or was a very weak signal in few cells (red arrow-heads). ZR, zona reticularis; $\mathrm{ZF}$, zona fasciculata; ZG, zona glomerulosa. 
Table 3 Total number of DHEA/DHEAS or PTEN positive and total cells per high power field in the ZR of women.

\begin{tabular}{|c|c|c|c|c|}
\hline & \multicolumn{4}{|c|}{ DHEA/DHEAS } \\
\hline & \multicolumn{2}{|c|}{$16-20$ years $(n=4)$} & \multicolumn{2}{|c|}{$41-43$ years $(n=3)$} \\
\hline & Positive & Total & Positive & Total \\
\hline & 9 & 20 & 5 & 23 \\
\hline & 18 & 24 & 9 & 20 \\
\hline & 3 & 29 & 0 & 19 \\
\hline & 23 & 23 & & \\
\hline Mean & 13.25 & 24 & 4.66 & 20.66 \\
\hline \pm S.D. & 8.96 & 3.74 & 4.41 & 2.08 \\
\hline
\end{tabular}

\begin{tabular}{|c|c|}
\hline \multicolumn{2}{|c|}{$16-20$ years $(n=4)$} \\
\hline Positive & Total $^{\mathrm{a}}$ \\
\hline 26 & 28 \\
\hline 31 & 35 \\
\hline 26 & 27 \\
\hline 2 & 28 \\
\hline 21.25 & 29.5 \\
\hline 13.05 & 3.70 \\
\hline
\end{tabular}

\begin{tabular}{|c|c|}
\hline \multicolumn{2}{|c|}{$41-43$ years $(n=3)$} \\
\hline Positive & Total $^{a}$ \\
\hline 19 & 23 \\
\hline 21 & 24 \\
\hline 18 & 24 \\
\hline 19.33 & 23.66 \\
\hline 1.53 & 0.58 \\
\hline
\end{tabular}

Total number (hematoxylin counterstained) subtracted by the number of positive cells for DHEA/DHEAS are negative cells for DHEA/DHEAS, and vice versa for PTEN. The comparisons were between younger adults (with higher blood DHEAS levels) and the age group with significant percent of cases $<2040 \mathrm{nmol} / \mathrm{L}$.

a $P<0.05$.

consequences in aging for skin, muscle and bone metabolism. Similarly, changes in the ZR were reported previously as a reduced mass in older American men (54-90 years) in relation to that of younger men (20-29 years) (28). These studies provide novel mechanistic insights regarding the adaptive changes in androgenesis and timing of viability of ZR cells. Given the important role of mitochondria in DHEA production, oxidative metabolism in mitochondria upon aging may increase reactive oxygen species, which may cause DNA damage and mutagenesis (29). In the presence of high levels of reactive oxygen species, mitochondria become damaged, accumulate cytotoxic mediators, and induce cell death (30). Moreover, degeneration and cell death in the ZR may be associated with local inflammatory process and oxidative stress, which had been previously reported in Japan by Takayanagi et al. (31). It could be also associated with higher susceptibility of all cortical layers to develop adrenocortical carcinoma (ACC). This hypothesis may explain why adrenopause onset and ACC incidence peaks are close in some countries. In particular, the ACC peak is earlier in the adjacent state of São Paulo at the end of the fourth decade, in higher proportion in females, noncarriers of the germline variant TP53 R337H, which rules out influence of this variant (32). Additional information about the TP53 R337H mutation in the South and South-East Brazil and the discussion about PTEN is provided in the Supplementary Materials (see section on supplementary materials given at the end of this article).

The characterization of the exact age limits of adrenopause onset must consider three important features: genetic background, geographical environment and sex. Ethnicity influence was highlighted by the work of Crawford et al. (16), showing different DHEAS levels in women of the same age albeit different ethnicities and higher threshold: African American (<2440 nmol/L),
Hispanic (<2990 nmol/L), Japanese $(<3530$ nmol/L), Caucasians $(<3940 \mathrm{nmol} / \mathrm{L})$ and Chinese women $(<5160$ nmol/L). In turn, altitude, an environmental factor, was found to influence DHEAS levels in women (17). Finally, sex-specific differences also exist, as females exhibit lower DHEAS levels earlier in the aging process as reported elsewhere $(15,17,27,33)$. AOT, described herein as blood DHEAS levels $<2040 \mathrm{nmol} / \mathrm{L}$, in more than $35 \%$ of the women in the 40s, was reported among older women in Italy (33), Germany (34), France $(35,36)$, and the USA (15, $37)$.

Certain limitations are to be noted in this study. Adrenals from other ages and sex matched with blood DHEAS levels should be further evaluated a longitudinal cohort. We note that caution must be observed when drawing mechanistic insights, such as the potential relationship between adrenopause and ACC risk. Moreover, further research is necessary to define the short survival period of the ZR in addition to the factors specifically regulating DHEA production and cell death in the ZR.

\section{Conclusion}

Whereas no substantial differences with previous studies were observed with regard to early DHEAS increases in girls, we found that a substantial proportion of the females aged 41-45 years (>35\%) exhibited early adrenopause onset characterized by DHEAS $<2040 \mathrm{nmol} / \mathrm{L}$ and decreased ZR cell number. However, this was not a longitudinal study since we used three different cohorts. In conclusion, adrenopause is an additional burden for a significant number of middle-aged women during the menopausal transition. Significant reduction of sex steroids may accelerate the aging process and cause skin

This work is licensed under a Creative Commons Attribution-NonCommercial-NoDerivatives 4.0 Internationab ficense.ifica . com at 04/26/2023 11:33:09AM 
and vaginal atrophy, bone and muscle loss. Further studies should evaluate these systems and develop replacement therapies.

\section{Supplementary materials}

This is linked to the online version of the paper at https://doi.org/10.1530/ EC-20-0416.

\section{Declaration of interest}

The authors declare that there is no conflict of interest that could be perceived as prejudicing the impartiality of the research reported.

\section{Funding}

This work was supported by Coordenação de Aperfeiçoamento de Pessoal de Nível Superior - Brasil (CAPES) Finance code 001; Conselho Nacional de Desenvolvimento e Pesquisa (CNPq, Brazil) and the CNRS EXPOGENCANCER. International Associated Laboratory (LIA).

\section{Acknowledgements}

The authors are grateful to Clinics Hospital and Division of Pathology of Federal University of Paraná for their support.

\section{References}

1 Mesiano S \& Jaffe RB. Developmental and functional biology of the primate fetal adrenal cortex. Endocrine Reviews 199718 378-403. (https://doi.org/10.1210/edrv.18.3.0304)

2 Xing Y, Lerario AM, Rainey W \& Hammer GD. Development of adrenal cortex zonation. Endocrinology and Metabolism Clinics of North America 201544 243-274. (https://doi.org/10.1016/j. ecl.2015.02.001)

3 Hammer GD, Parker KL \& Schimmer BP. Minireview: transcriptional regulation of adrenocortical development. Endocrinology 2005146 1018-1024. (https://doi.org/10.1210/en.2004-1385)

4 Belgorosky A, Baquedano MS, Guercio G \& Rivarola MA. Expression of the IGF and the aromatase/estrogen receptor systems in human adrenal tissues from early infancy to late puberty: implications for the development of adrenarche. Reviews in Endocrine and Metabolic Disorders 200910 51-61. (https://doi.org/10.1007/s11154-0089105-1)

5 Mason JI \& Rainey WE. Steroidogenesis in the human fetal adrenal: a role for cholesterol synthesized de novo. Journal of Clinical Endocrinology and Metabolism 198764 140-147. (https://doi. org/10.1210/jcem-64-1-140)

6 Ishimoto H \& Jaffe RB. Development and function of the human fetal adrenal cortex: a key component in the feto-placental unit. Endocrine Reviews 201132 317-355. (https://doi.org/10.1210/er.20100001)

7 Suzuki T, Sasano H, Takeyama J, Kaneko C, Freije WA, Carr BR \& Rainey WE. Developmental changes in steroidogenic enzymes in human postnatal adrenal cortex: immunohistochemical studies. Clinical Endocrinology 200053 739-747. (https://doi.org/10.1046/ j.1365-2265.2000.01144.x)

8 Utriainen P, Jääskeläinen J, Romppanen J \& Voutilainen R. Childhood metabolic syndrome and its components in premature adrenarche. Journal of Clinical Endocrinology and Metabolism 200792 4282-4285. (https://doi.org/10.1210/jc.2006-2412)
9 Idkowiak J, Lavery GG, Dhir V, Barrett TG, Stewart PM, Krone N $\&$ Arlt W. Premature adrenarche: novel lessons from early onset androgen excess. European Journal of Endocrinology 2011165 189-207. (https://doi.org/10.1530/EJE-11-0223)

10 Corvalán C, Uauy R \& Mericq V. Obesity is positively associated with dehydroepiandrosterone sulfate concentrations at $7 \mathrm{y}$ in Chilean children of normal birth weight. American Journal of Clinical Nutrition 201397 318-325. (https://doi.org/10.3945/ajcn.112.037325)

11 Bae YJ, Zeidler R, Baber R, Vogel M, Wirkner K, Loeffler M, Ceglarek U, Kiess W, Körner A \& Thiery J. Reference intervals of nine steroid hormones over the life-span analyzed by LC-MS/MS: Effect of age, gender, puberty, and oral contraceptives. Journal of Steroid Biochemistry and Molecular Biology 2019193 1-7. (10.1016/j. jsbmb.2019.105409)

12 De Peretti E \& Forest MG. Pattern of plasma pregnenolone sulfate levels in humans from birth to adulthood. Journal of Clinical Endocrinology and Metabolism 197857 550-556. (https://doi. org/10.1210/jcem-57-3-550)

13 Guercio G, Rivarola MA, Chaler E, Maceiras M \& Belgorosky A. Relationship between the growth hormone/insulin-like growth factor-I axis, insulin sensitivity, and adrenal androgens in normal prepubertal and pubertal girls. Journal of Clinical Endocrinology and Metabolism 200388 1389-1393. (https://doi.org/10.1210/jc.2002020979)

14 Genazzani AR, Facchinetti F, Petraglia F, Pintor C, Bagnoli F, Puggioni R \& Corda R. Correlations between plasma levels of opioid peptides and adrenal androgens in prepuberty and puberty. Journal of Steroid Biochemistry 198319 891-895. (https://doi.org/10.1016/00224731(83)90030-4)

15 Orentreich N, Brind JL, Rizer RL \& Vogelman JH. Age changes and sex differences in serum dehydroepiandrosterone sulfate concentrations throughout adulthood. Journal of Clinical Endocrinology and Metabolism 198459 551-555. (https://doi. org/10.1210/jcem-59-3-551)

16 Crawford S, Santoro N, Laughlin GA, Sowers MF, McConnell D, Sutton-Tyrrell K, Weiss G, Vuga M, Randolph J \& Lasley B. Circulating dehydroepiandrosterone sulfate concentrations during the menopausal transition. Journal of Clinical Endocrinology and Metabolism 200994 2945-2951. (https://doi.org/10.1210/jc.20090386)

17 Gonzales GF, Góñez C \& Villena A. Adrenopause or decline of serum adrenal androgens with age in women living at sea level or at high altitude. Journal of Endocrinology 2002173 95-101. (https://doi. org/10.1677/joe.0.1730095)

18 Pena SD, Di Pietro G, Fuchshuber-Moraes M, Genro JP, Hutz MH, Kehd FS, Kohlrausch F, Magno LA, Montenegro RC, Moraes MO, et al. The genomic ancestry of individuals from diferent geographical regions of Brazil is moreuniform the expected. PLOS ONE 20116 1-9. (https://doi.org/10.1371/journal.pone.0017063)

19 Custódio G, Parise GA, Kiesel Filho N, Komechen H, Sabbaga CC, Rosati R, Grisa L, Parise IZS, Pianovski MAD, Fiori CMCM, et al. Impact of neonatal screening and surveillance for the TP53 R337H mutation on early detection of childhood adrenocortical tumors. Journal of Clinical Oncology 201331 2619-2626. (https://doi. org/10.1200/JCO.2012.46.3711)

20 Center for Disease Control and Prevention. BMI percentage calculator for child and teen. (available at: https://www.cdc.gov/ healthyweight/bmi/calculator.html). Accessed on 26 Nov 2019.

21 Onis M. World Health Organization reference curves. In the Free Obesity eBook. European Childhood Obesity Group - World Health Organization. (available at: http://ebook.ecog-obesity.eu/chaptergrowth-charts-body-composition/world-health-organizationreference-curves/). Accessed on 26 Nov 2019.

22 Sansal I \& Sellers WR. The biology and clinical relevance of the PTEN tumor suppressor pathway. Journal of Clinical Oncology 200422 2954-2963. (https://doi.org/10.1200/JCO.2004.02.141) 
23 Chang CJ, Mulholland DJ, Valamehr B, Mosessian S, Sellers WR \& Wu H. PTEN nuclear localization is regulated by oxidative stress and mediates p53-dependent tumor suppression. Molecular and Cellular Biology 200828 3281-3289. (https://doi.org/10.1128/MCB.00310-08)

24 Fogaça RL, Alvarenga LM, Woiski TD, Becker-Finco A, Teixeira KN, Silva SK, de Moraes RN, Noronha L, Noiray M, de Figueiredo BC, et al. Biomolecular engineering of antidehydroepiandrosterone antibodies: a new perspective in cancer diagnosis and treatment using single-chain antibody variable fragment. Nanomedicine 201914 689-705. (https://doi.org/10.2217/nnm-2018-0230)

25 Parise IZS, Parise GA, Noronha L, Suraky M, Woiski TD, Silva DB, Costa TEB, Del-Vale MHCP, Komechen H, Rosati R, et al. The prognostic role of CD8+ T lymphocytes in childhood adrenocortical carcinomas compared to Ki-67, PD-1, PD-L1, and the Weiss score. Cancers 201911 1-16. (https://doi.org/10.3390/cancers11111730)

26 Sklar CA, Kaplan SL \& Grumbach MM. Evidence for dissociation between adrenarche and gonadarche: studies in patients with idiopathic precocious puberty, gonadal dysgenesis, isolated gonadotropin deficiency, and constitutionally delayed growth and adolescence. Journal of Clinical Endocrinology and Metabolism 198051 548-556. (https://doi.org/10.1210/jcem-51-3-548)

27 Benetti-Pinto CL, Bedone AJ \& Magna LA. Evaluation of serum androgen levels in women with premature ovarian failure. Fertility and Sterility 200583 508-510. (https://doi.org/10.1016/j. fertnstert.2004.09.015)

28 Parker CRJ, Mixon RL, Brissie RM \& Grizzle WE. Aging alters zonation in the adrenal cortex of men. Journal of Clinical Endocrinology and Metabolism 199782 3898-3901. (https://doi. org/10.1210/jcem.82.11.4507)

29 Maynard S, Schurman SH, Harboe C, de Souza-pinto NC \& Bohr VA. Base excision repair of oxidative DNA damage and association with cancer and aging. Carcinogenesis 200930 2-10. (https://doi org/10.1093/carcin/bgn250)

30 Lee J, Giordano S \& Zhang J. Autophagy, mitochondria and oxidative stress: cross-talk and redox signalling. Biochemical Journal 201244 523-540. (https://doi.org/10.1042/BJ20111451)
31 Takayanagi R, Kato K \& Ibayashi H. Relative inactivation of steroidogenic enzyme activities microsomes by lipid peroxidation. Endocrinology 1986119 464-469. (https://doi.org/10.1210/endo-1192-464)

32 Latronico AC, Pinto EM, Domenice S, Fragoso MC, Martin RM, Zerbini MC, Lucon AM \& Mendonca BB. An inherited mutation outside the highly conserved DNA-binding domain of the p53 tumor suppressor protein in children and adults with sporadic adrenocortical tumors. Journal of Clinical Endocrinology and Metabolism 200186 4970-4973. (https://doi.org/10.1210/ jcem.86.10.7957)

33 Ravaglia G, Bernardi PM, Forti C, Maioli F, Pratelli F, Pizzoferrato A \& Gasbarrini G. The relationship of dehydroepiandrosterone sulfate (DHEAS) to endocrine-metabolic parameters and functional status in the oldest-old. Results from an Italian study on healthy free-living over-ninety-years-olds. Journal of Clinical Endocrinology and Metabolism 199681 1173-1178. (https://doi.org/10.1210/ jcem.81.3.8772596)

34 Lacruz ME, Emeny RT, Bickel H, Cramer B, Kurz A, Bidlingmaier M, Huber D, Klug G, Peters A \& Ladwig KH. Mental health in the aged: prevalence, covariates and related neuroendocrine, cardiovascular and inflammatory factors of successful aging. BMC Medical Research Methodology 201010 36. (https://doi.org/10.1186/14712288-10-36)

35 Legrain S, Berr C, Frenoy N, Gourlet V, Debuire B \& Baulieu EE. Dehydroepiandrosterone sulfate in a long-term care aged population. Gerontology 199541 343-351. (https://doi.org/10.1159/000213706)

36 Berr C, Lafont S, Debuire B, Dartigues JF \& Baulieu EE. Relationships of dehydroepiandrosterone sulfate in the elderly with functional, psychological, and mental status, and short-term mortality: a French community-based study. PNAS 199693 13410-13415. (https://doi. org/10.1073/pnas.93.23.13410)

37 Barret-Connor E, Khaw KT \& Yen SSC. A prospective study of dehydroepiandorsterone sulfate, mortality, and cardiovascular disease. New England Journal of Medicine 1986315 1519-1524. (https://doi.org/10.1056/NEJM198612113152405)

Received in final form 24 September 2020

Accepted 14 October 2020

Accepted Manuscript published online 14 October 2020 https://ec.bioscientifica.com https://doi.org/10.1530/EC-20-0416 (c) 2020 The authors Published by Bioscientifica Ltd
This work is licensed under a Creative Commons Attribution-NonCommercial-NoDerivatives 4.0 Internationab ficense.ifica . com at 04/26/2023 11:33:09AM 